\title{
PARENTHOOD, ALTRUISM, AND THE MARKET: A CRITIQUE OF ESSENTIALIST CONSTRUCTIONS OF WOMEN'S NATURE IN COMMERCIAL SURROGACY
}

\begin{abstract}
JESÚS MORA $*$,1
Abstract: Commercial surrogacy has become an increasingly popular path to parenthood around the world. Yet, critics have raised concerns about the practice's implications for gender inequality. This paper critically assesses commercial surrogacy's reliance on, and reinforcement of, common narratives about women's natural disposition to sacrifice themselves for others. These narratives have historically served to justify disadvantages for women as workers, both within and outside the household. Their presence in commercial surrogacy agreements suggests that, even if we can characterise commercial surrogacy as an alternative (as opposed to traditional) method for family formation, the same social stereotypes that have historically entrenched women's inequality in traditional families are still highly relevant for the practice's functioning.
\end{abstract}

Keywords: commercial surrogacy; reproduction; family; commodification; altruism; gender equality.

Summary: 1. INTRODUCTION. 2. COMMERCIAL SURROGACY: DEFINITION, ACTORS, AND CURRENT DIMENSION. 3. MAKING COMMERCIAL SURROGACY SOCIALLY ACCEPTABLE. 3.1. Justifying kinship. 3.2. Altruistic motivations. 4. UnBALANCED ALTRUISM: SECURING THE INTERESTS OF IPS AND AGENCIES. 5. COMMERCIAL SURROGACY AND GENDER INEQUALITIES. 6. Commercial SURRogacy, the SOCIAL VALUE OF CARE WORK, AND GENDER INEQUALITIES. 7. CONCLUSION.

\section{INTRODUCTION}

Commercial surrogacy has received a great deal of attention in recent ethical and philosophical discussions. The practice has become increasingly popular in the last two decades, giving rise to a booming industry and to some instances of ethnographic work analysing its implications from different perspectives, especially in those countries where commercial surrogacy is legal. One such country is India, which until recently was considered one of the main destinations for couples looking to enter into commercial surrogacy agreements. Estimates suggest that the Indian commercial surrogacy industry comprised as many as 200,000 assisted reproductive technology clinics with a revenue of around USD 2.3 billion in 2012 (Jaiswal, 2012). The rapid expansion of commercial

\footnotetext{
* Carlos III University of Madrid, Ph. D. in Advanced Studies in Human Rights, jesuspmora14@gmail.com. ${ }^{1} \mathrm{Ph}$. D. in Advanced Studies in Human Rights in the Carlos III University of Madrid. Final thesis advisor for the Masters in Human Rights at UNIR. I would like to thank Professor Oscar Pérez de la Fuente for his useful advice and comments. This article is also the result of multiple corrections and reviews from anonymous referees that have helped enormously to improve its content. I would also like to thank Will Masters for his careful grammar review and copyediting, and all the professors that have enriched my knowledge about gender equality, especially Paula Casal and Ana de Miguel.
} 
surrogacy has prompted concerns about the risks involved for the health of surrogate mothers, whose lives can be put at risk, and the conditions in which they gestate and give birth (Riben, 2015) ${ }^{2}$. Claims about the Indian commercial surrogacy industry's involvement in the exploitation of women led to a parliamentary Bill prohibiting paid surrogacy and establishing a restrictive "altruistic surrogacy" framework (The Surrogacy (Regulation) Bill, 2019)3.

In countries such as the United States, Israel, and Russia, authors have studied the status, concerns, and relationships of the different parties involved in commercial surrogacy agreements. In this paper, I intend to focus on the implications of commercial surrogacy for gender inequalities. I will achieve this by analysing narratives that are particularly prominent in commercial surrogacy within specific contexts. Attaching monetary compensation to gestation might, at first glance, be beneficial for gender equality, as it appears to challenge old-fashioned assumptions about care work as a female, undervalued form of labour. Yet, I will try to argue that the practice's reliance on some traditional narratives about women's nature might, in some contexts, have detrimental implications for gender equality. In many ways, commercial surrogacy's functioning relies on narratives that encourage women's participation as surrogates and help fulfil the interests of intended parents and agencies by appealing to oppressive assumptions about women's (allegedly) self-sacrificing nature.

Commercial surrogacy involves different actors - surrogates, intended parents, agencies, lawyers, clinics' staff, translators, psychologists, etc.- , all of whom rely on different, sometimes even contradictory, narratives (Ragoné, 1996, p. 362; Pande, 2010, p. 307). In section 2, I will refer to commercial surrogacy as a global phenomenon and detail some of its main actors' functions in these agreements. In section 3, I will address the importance of moral frames in commercial surrogacy agreements by analysing some prominent narratives intended to make the practice socially acceptable (Ragoné, 1996; Pande, 2010; Teman, 2010; Rudrappa and Collins, 2015; Smietana, 2017). Such narratives include the parties' conceptions about kinship and the adequate bases to establish parenthood (see Strathern 1992; Ragoné, 1996; Teman, 2003, 2010; Thompson, 2005; Berend, 2016; Jacobson, 2016). These kinship narratives, often adapted by the parties based on their capacity to justify the intended parents' relatedness to the foetus or child in their social environments, highlight the importance of cultural legitimacy for the parties' own characterisation and justification of commercial surrogacy agreements. In addition to kinship narratives - and relying on the same views about the importance of moral frames-, I will address a second type of narrative, prominent in this type of contract,

\footnotetext{
${ }^{2}$ Some researchers also report that Indian clinics have often taken advantage of illiterate surrogate mothers and have exercised different kinds of psychological pressure against them, including isolation from their families (Fontanella-Khan, 2010).

${ }^{3}$ Eligibility criteria for intended parents include Indian nationality, proven infertility, lack of healthy offspring, being of a young age, and marriage continuity; surrogates are required to be a relative of the intended parents, to already have children of their own, to act as surrogates only once in their lifetime, and to meet certain age, medical, and psychological fitness requirements (The Surrogacy (Regulation) Bill, 2019).
} 
in relation to the parties' motivations to enter into commercial surrogacy agreements. I will attempt to demonstrate the importance of gift relations and altruistic motivations in justifying both the intended parents' and the surrogates' decision to enter into commercial surrogacy contracts. These narratives of altruism, like the above strategies to establish kinship between the intended parents and the foetus or child, are fundamental to make commercial surrogacy agreements acceptable in the parties' social environments.

Alongside social acceptability, narratives of altruism are important in commercial surrogacy agreements for another reason. As I will explain in Section 4, in some contexts it is common for the parties to refer to altruism and self-sacrifice as natural inclinations for women in general, and for surrogates in particular. Especially when convenient for the interests of intended parents and surrogacy agencies, altruistic motivations are depicted as a one-sided phenomenon, to the extent that surrogates are expected to be naturally inclined to sacrifice their interests just for the sake of helping others, without upholding any legitimate expectation to be reciprocated. These narratives about women's natural disposition to constantly sacrifice themselves for others, common in some countries' surrogacy industries, make commercial surrogacy reliant on a set of discursive strategies that have been used, historically, to justify women's oppression and gender inequalities, especially in the distribution of care-related work between men and women. Drawing on this second reason for the importance of narratives of altruism in commercial surrogacy, in Section 5 I will argue that commercial surrogacy, as it exists nowadays in certain contexts, entrenches stereotypes about women's nature that have traditionally worked as foundations for gender inequality.

According to authors such as Jacobson (2016), commercial surrogacy's disadvantageous implications for women in general, and surrogates in particular, can be rooted in cultural anxieties about the commodification of reproduction. This argument appears to indicate that, if we are concerned with the surrogates' position in these agreements, and with gender inequalities from a wider social perspective, we should normalise the presence of market transactions in the field of reproduction and the consideration of paid pregnancy as regular remunerated work. In Section 6, I will address this proposal and argue, in response to Jacobson, that the disadvantages currently suffered by surrogates, like other gender inequalities in reproductive work, arise from social assumptions about care work that are not entirely rooted in fears about the commodification of gestation. Naturalising gestation as a regular form of remunerated work need not dispel current social assumptions that, I shall argue, are detrimental to women's equality as workers both within and outside the household. Furthermore, I will contend that some social fears regarding the commodification of reproduction can be legitimate. As a consequence, I will propose alternative routes to overcome oppressive cultural narratives about women's nature and their position as workers that avoid those worrisome implications.

\section{COMMERCIAL SURROGACY: DEFINITION, ACTORS, AND CURRENT DIMENSION}

Let us start by providing a definition of commercial surrogacy and some relevant pieces of knowledge about its current dimensions around the world. Commercial surrogacy is a type of contract under which a woman agrees to become pregnant, and carry that 
pregnancy to term, for another person or couple in exchange for money and, upon the birth of the child, relinquish her parental rights, so that the commissioning party may raise the child as their own (Anderson, 1990, p. 71; Bernardo and Bernardo, 2007, p. 409). Actors in commercial surrogacy agreements play different roles: the surrogate ${ }^{4}$ gestates the child and agrees to relinquish her rights when the baby is born; the intended parents (IPs) pay a varying amount of money in exchange for exclusive parental rights over the child; brokers and agencies try to make sure that the agreement is carried to term (Anderson, 1990, p. 74); finally, clinics, reproductive endocrinologists (REs), and other medical staff perform all the assisted reproduction techniques necessary to create and sustain a successful pregnancy (see Jacobson 2016, p. 24), in some contexts also acting as "gatekeepers", controlling who can and cannot demand information about the surrogates' situation (see Weis 2019). Commercial surrogacy agreements can take two different forms: traditional surrogacy and gestational surrogacy. In traditional surrogacy, the surrogate is impregnated with the intended father's sperm or has the embryo implanted in her uterus after having her egg fertilised via in-vitro fertilisation. In traditional surrogacy, the surrogate provides the egg and gestates (Dillaway, 2008, pp. 302-303). In gestational surrogacy, the surrogate only undertakes the labour of gestation, as the genetic material is provided entirely from external sources - either from the intended mother or another woman who has agreed with the IPs or the agency to provide an egg for fertilisation (pp. 302-303). In these cases, the surrogate is implanted with a pre-embryo formed from donated gametes by means of invitro fertilisation (Satz, 1992, p. 113).

In the United States, where commercial surrogacy has attracted significant media and academic interest, surrogacy agreements alone had produced around 2,000 births by 1990 (Nelkin, 1992, p. 45). Authors like Jacobson (2016, p. 11) acknowledge that it is still difficult to capture "accurate rates of surrogacy", since no official data is currently available. Nevertheless, Jacobson's own estimates suggest that since the late 1970s the number of children born as a result of commercial surrogacy agreements ranges from 10,000 to 31,000 , and that today around 1,500 babies are born from paid surrogacy contracts every year (p. 11). The fees paid by IPs vary from agreement to agreement but, according to Jacobson (p. 32), non-medical expenses (including payments for agencies, lawyers, REs, and the surrogate's fee) range between $\$ 60,000$ and $\$ 80,000$, with an additional $\$ 20,000-\$ 30,000$ covering medical expenses. Other estimates suggest that commercial surrogacy agreements in the U.S. can cost up to $\$ 150,000$, and that "[c]ontingencies like invasive procedures, multiple pregnancy, or Caesarean section push the cost further up" (Birenbaum-Carmeli and Montebruno 2019, p. 2461). In recent years, commercial surrogacy has become a global industry and, since the early 2000 s, poor countries like India have been among the preferred destinations for citizens of states where the practice

\footnotetext{
${ }^{4}$ In some contexts, like India, it is common for ethnographic researchers to refer to the surrogate as the "surrogate mother" or the "birthing mother" (see Pande, 2010; Rudrappa and Collins, 2015; Rudrappa 2016). Yet, as highlighted by an anonymous reviewer, that nomenclature does not fit the surrogates' common descriptions of their experience in contexts like the United States, where they try to justify their decision to enter a surrogacy agreement by emphasising that they are not the mother of the child they carry (see Jacobson, 2016, p. 68).
} 
is either prohibited or too expensive, but who still want to become parents through these types of arrangements. Economically, commercial surrogacy has proven to be a lucrative business, with the industry's worth being estimated in $\$ 6.4$ billion by 2012 (Fenton-Glynn, 2019).

Given its surging popularity in different countries, the practice's social and political implications have attracted the attention of academics. In India, critics have referred to the role of race, class, and gender in the industry's functioning (Rudrappa and Collins, 2015; Limki, 2018), as well as to common cultural stereotypes that stigmatise Indian surrogates (Pande, 2010). The idea of stigmatisation, stemming from traditional conceptions about reproduction and the family, has also been analysed in U.S. ethnographies, especially in what concerns its impact on surrogates' discourses about their decision to gestate someone else's child (see Jacobson, 2016). In Israel, Teman (2010) has addressed the impact of the country's natalist policies and the national significance of motherhood - within the context of the Israeli-Palestinian conflict - on the growth of its local surrogacy industry. In Russia, attention has been given to the power relations and the control exercised by agencies and clinics over surmamas (Weis, 2019), and to the impact of Soviet conceptions about childbearing as a job to be encouraged by economic support from the state (Smietana, Rudrappa and Weis, 2021).

\section{MAKING COMMERCIAL SURROGACY SOCIALLY ACCEPTABLE}

Many of the authors responsible for the ethnographies detailed above have referred to the cultural anxiety around the commodification of gestation (Jacobson, 2016, pp. 71, 177; Smietana, Rudrappa and Weis, 2021, p. 8) that surrogacy has generated. As a result of that anxiety, the parties involved in commercial surrogacy have based their decisions in different moral frames. Relying on Goffman's (1974, p. 21) definition of “frames", scholars like Rudrappa and Collins (2015, p. 943) have highlighted the importance of those "schemes of interpretation that enable actors 'to locate, perceive, identify, and label' events in their social worlds". In commercial surrogacy, moral frames operate on different fronts. Altruism, which is the main focus of this paper, is one of them. Alongside altruism, the parties also develop different strategies to establish kinship relationships between the IPs and the foetus or child. These strategies can help us understand how important it is for the parties to escape the accusation that commercial surrogacy agreements commodify human relations in reproduction and parenthood.

\subsection{Justifying kinship}

Narratives about kinship play a major role in commercial surrogacy and other reproductive technologies, like egg donation and in-vitro fertilisation, because these practices "challenge biological essentialism through the separability of egg, gestation, and biological mother" (Thompson 2005, 166). As identified by Dillaway (2008), commercial surrogacy separates the three main aspects of motherhood: the genetic, the gestational, and the social. The genetic aspect belongs to "the woman who contributes the egg that becomes the foetus", which in the case of traditional surrogacy is the surrogate, and in the case of gestational surrogacy is a woman different from the surrogate (either the intended mother, 
an egg donor, or another woman who gets paid in exchange for her ova). The gestational aspect is assumed by the surrogate, "who carries the foetus to term, nourishes it for nine months, and gives birth to the child". The social aspect corresponds to the person(s) "who ultimately raise(s) the child and assume(s) the responsibility of caregiving" (Dillaway, 2008, p. 307), namely, the IPs 5 .

In recent years, the separation conceptualised by Dillaway has been further enhanced by the proliferation of gestational surrogacy in major commercial surrogacy markets (see Jacobson, 2016, p. 11 for the U.S.; Teman, 2010, p. 2 for Israel; Rudrappa and Collins 2015, p. 939, for India; and Smietana, Rudrappa, and Weis, 2021, p. 5 for Russia). According to ethnographic research on gestational surrogacy, the parties in commercial surrogacy agreements have developed different strategies to justify genetic and gestational connections to the foetus (and, later, the baby), even when genetic material and gestation are provided by women different from the intended mother. For instance, reports show that some intended mothers prefer genetic material from women who are culturally, ethnically, or socially close to them whenever they cannot provide the ova (Thompson, 2005, p. 168).

The genetic aspect is also emphasised by surrogates as a way to justify their decision to give away the child after birth. Berend (2016, p. 74) notes that it is common, among gestational surrogates, to highlight lack of genetic connection to distinguish their case from traditional surrogates'. Even though this is not normally intended as a critique to traditional surrogates, it portrays the view that giving away a child with whom they share a genetic connection would be much more difficult (pp. 74-75). This view is also present among Indian surrogates and reinforced by other agents in the industry like physicians and nurses (Pande, 2010, pp. 307-308). As Dow's research on opinions about commercial surrogacy in Scotland shows, even in jurisdictions where the practice is illegal, the absence of genetic connection with the child tends to make the surrogates' decision more understandable in the eyes of society (Dow, 2015, p. 12).

This tendency amongst intended mothers, surrogates, and other actors in commercial surrogacy to emphasise genetic connection makes it easier for them to justify their decisions in their social environment. At the same time, the importance they attach to genetic connection is often conveniently adapted to their situation, not only in surrogacy, but in other reproductive technologies. As reported by Thompson in the U.S., different aspects of motherhood are emphasised or deemphasised in common narratives surrounding assisted reproductive technologies in the same country, depending on their convenience when establishing parenthood. The author highlights how, in the context of in-vitro fertilisation via egg donation, it is common to stress the importance of the time spent in gestation, the custodial role of the mother, and the experiential aspects of pregnancy (Thompson, 2005, p. 168).

\footnotetext{
${ }^{5}$ Legal procedures to award custody rights to the IPs vary from one jurisdiction to another. While in some countries IPs have custody recognised from the moment of birth, in others, like Thailand, legal custody at birth is awarded to the surrogate, and only recognised to IPs after "a timely and costly parental rights transfer process that is undesirable to intended parents" (Caamano 2016, p. 580).
} 
Parties in commercial surrogacy agreements have also adopted strategies to build gestational ties between unborn children and their intended mothers. In Israel, this is done by engaging in extremely intimate relations with surrogates, which has led Teman to develop the idea of "the shifting body": a psychological extension of the symptoms of pregnancy from surrogates to intended mothers that allows the latter "to construct a pregnant identity and to gradually confer maternal status" (Teman, 2010, p. 147). For Israeli intended mothers, according to the author, (pp. 178-179), "it is not enough ... to have a genetic connection; instead, she has to engage in a pregnancy by proxy to embody the gestational environment 'carrying' her child, and to 'replace' her surrogate in a prosthetic process of "pseudoprocreation"". This can be explained by the prevalence of essentialist Western ideals of femininity that construct the experiences associated to childbirth and pregnancy as "standards for proving "normal womanhood"' (p. 152). Even in this context, genetic connection is still relevant in cases where the relation between the surrogate and the intended mother becomes so close that it is complicated for their social environment to establish who is the mother. When this occurs, Teman (2010, p. 158) reports, intended mothers often appeal to their genetic contribution to dispel doubts about their standing.

This suggests that parties in commercial surrogacy agreements alter their proclaimed views about the adequate bases for parenthood depending on how convenient they are to justify their situation. Recent emphasis on procreative intent among IPs and surrogates further supports this claim. According to Thompson (2005, p. 172), "procreative intent (tagged by intention, payment, and often the role of class in the court's perception of a child's best interests)" has become more important in courts' decisions about legal custody. Intent has also emerged as a popular foundation for parenthood among U.S. surrogates who want to legitimise their actions. Berend (2016, p. 78) reports how "both gestational and traditional surrogates see the fervent desire for a baby as the basis of parenthood". For U.S. surrogates, it seems appropriate to emphasise intent to the detriment of genetic connection because "many IPs use or end up using donated gametes" (p. 73).

The need to rely on these narratives to establish kinship seems to emerge from the social anxiety about the possibility of commercial surrogacy constituting the commodification of babies (Smietana, Rudrappa and Weis, 2021, p. 8). Expected social criticism, arising from the perception that IPs are paying for custody rights over babies and that surrogates are selling custody rights over their own children (see Jacobson, 2016, p. 58), encourages the parties in surrogacy agreements to emphasise the importance of genetic connection, gestation, or intent depending on how they can serve to justify their decisions.

\subsection{Altruistic motivations}

Narratives that establish relatedness between children and intended parents are not the only relevant moral frame used by parties, in contexts where commercial surrogacy agreements are legal, to ease social anxieties about the commodification of human relationships in reproduction and parenthood. Another prominent discourse, especially in India and the U.S., depicts the parties as being motivated by a concern to improve each other's position, which leads them to emphasise altruistic motivations when justifying their 
decision to take part in a commercial surrogacy agreement. These references to altruism, like appeals to genetic relatedness or intent, help the parties dispel social conceptions of commercial surrogacy as a purely commercial exchange of money for gestation and custody rights that commodifies reproduction (Smietana, Rudrappa and Weis, 2021, p. 8).

As defined by Cohen, commodification amounts to "treating people according to a market norm - the norm that says they are to be dispensed with if they cannot produce at a rate which satisfies market demand" (Cohen, 2000, p. 181). Cohen's view is that commodification is the equivalent of a market transaction in which human beings treat each other based entirely on their utility to create a certain benefit. This type of treatment entails, for the author, turning "human producers into commodities" (p. 181). In Cohen's perspective, this form of treatment is particularly objectionable when it occurs against a background of inequality, namely, when some people treat others as commodities through the exercise of power over them (Vrousalis, 2012, p. 158). As an alternative, the author defends a form of reciprocity, "communal reciprocity", that he defines as "the antimarket principle according to which I serve you not because of what I can get in return, but because you need or want my service, and you, for the same reason, serve me" (Cohen, 2009, p. 39). Following Cohen's insights, commodification can be defined, roughly, as the treatment of human beings as commodities within market transactions and against a background of inequality that allows one of the parties to exercise power over the other.

This broad definition of commodification can be further specified, when analysing markets in human reproduction, by adding a reference to the body, as the distinct human component that is subject to this form of treatment. In Nancy Scheper-Hughes's approach to markets in reproduction, commodification refers to "all capitalised economic relations between humans in which human bodies are the token of economic exchanges that are often masked as something else-love, altruism, pleasure, kindness" (Scheper-Hughes, 2001, p. 2). This "masking" of commodification as "something else", it should be noted, need not always be complete, as it may be possible for the parties to acknowledge being motivated by the individual obtainment of benefits and, at the same time, highlight that those benefits are not the only, perhaps not even the main, motivation leading them to enter commercial surrogacy agreements.

Common discourses among U.S. surrogates reported in ethnographic research are a good example of this partial decommodification. According to Jacobson, many surrogates justify their decision to gestate somebody else's child by appealing to an empathic feeling towards an infertile person in their close social circle (Jacobson, 2016, p. 53). That feeling figures among the most popular reasons, according to Jacobson's work, mentioned by surrogates as encouraging their decision to help other infertile couples. That does not mean that surrogates never mention monetary compensation as a reason to get involved in surrogacy. In particular, their demand for compensation is sometimes understood as a way to reinforce their position and avoid being viewed as someone that people can take advantage of (p. 61). Yet, surrogates emphasise that monetary compensation alone would not be sufficient for them to accept the daily sacrifices that carrying a child for someone else entails. Interestingly, one of the surrogates in Jacobson's study states: "I don't know many people who would go through this much for a job. This is more a personal, fulfilling thing 
that I want to do for someone else" (p. 65). This narrative was also reported in Ragoné's earlier studies (see 1996, p. 356) and in Berend's more recent research on surrogates' online interactions (see 2016, p. 65). Once again, according to Jacobson, appeals to altruistic motivations enhance the social acceptability of the surrogates' decision: "Downplaying compensation allows surrogates to distance themselves from [negative images] and to present a more positive framing of their motivations: one based on altruism and gift giving, rather than money making - and one that acknowledges the labor involved but does not frame that labor as a route to quick money" (Jacobson, 2016, p. 60).

These narratives, that conceptualise U.S. surrogates' relationships with IPs as something beyond being merely a party to a contract, are further reinforced by their acknowledged desire to establish a connection with IPs beyond commercial transactions (see Berend 2016, pp. 64-65; Smietana, Rudrappa, and Weis, 2021, p. 13). Such a desire is also expressed by Israeli surrogates, who consider "chemistry" (feeling naturally drawn to someone) to be fundamental in their preference for certain candidate IPs over others (Teman, 2010, p. 136). Likewise, Indian surrogates resist "the commercial and contractual nature of their relationships by establishing or imagining a relationship with the couples hiring them" (Pande, 2010, p. 307). These desires to depict their relationships with IPs as something beyond contractual exchanges are strongly influenced by cultural conceptions about the adequate motivations for gestation and reproduction in each of those countries ${ }^{6}$.

Surrogates are not the only ones to justify their involvement in surrogacy by appealing to motives beyond simply obtaining a benefit from others. India's case is very telling regarding the IPs' need to introduce motivations beyond self-interest in justifying their decision, especially when they come from economically advantaged countries. As suggested by Rudrappa and Collins (2015), the large economic differences between Indian surrogates and the commissioning individuals or couples fuel the need for IPs to introduce economic, aid-related motivations in justifying their preference for India's surrogacy industry, which provides much cheaper deals than, for example, commercial surrogacy in the U.S. This type of justifications is encouraged by agencies, which commonly depict Indian women as "poor mothers who are victims of their culture, dependent on men in their families, and inextricably tied to their familial and kinship networks" (p. 948). This allows IPs to "understand themselves as moral social actors who do not exploit surrogate mothers", but rather "ease the latter's entry into better lives". In turn, this helps "remove the anxiety surrounding the exchange of money for babies and

\footnotetext{
${ }^{6}$ Russia represents, in this regard, a telling example of the influence of context, since, as reported by Smietana, Rudrappa, and Weis (2021, p. 11), the expectation of friendship or altruistic motivation is not considered necessary to make surrogacy agreements more socially palatable. Rather inversely, surrogate recruits are "expected to have a business attitude" and, "[i]n order to prevent arrangements from getting messy, agencies [advise] client parents to avoid developing friendships with their surrogacy worker" (p. 11). For this reason, Russia's case should be discounted, as an exception, in discussions about the interactions of altruism and commodification in commercial surrogacy like the one presented in this section. Consequently, the analysis I will develop here does not intend to apply to Russia's commercial surrogacy industry. Nonetheless, I will refer to it again further below, when discussing its implications for alternative scenarios regarding the legal status of commercial surrogacy.
} 
allow[s] surrogacy agencies and clients to understand themselves as kind-hearted actors with generous intentions" (p. 948).

In contexts where reproduction and gestation are not considered adequate spaces for market transactions, narratives of altruism, friendship, and gift-giving help the parties in commercial surrogacy agreements make their decisions more socially justifiable. When combined with narratives about kinship, narratives of altruism help the parties escape a common understanding of commercial surrogacy among its critics, as acquiring legal custody over someone else's baby by means of a purely commercial transaction (see Anderson 1990; 2000). Kinship narratives challenge the first italicised element by affirming that the commissioned child is already the IPs' (because of their genetic connection, their pregnancy by proxy, or their procreative intent), and the surrogates' pregnancy only a temporary arrangement with no relevance to establish parenthood. Narratives about altruism challenge the second italicised element by appealing to noncommercial motivations. Those motivations dispel concerns about the parties being moved by selfishness, in contexts where common cultural understandings about gestation and reproduction consider them incompatible with motivations that are typical in market transactions.

\section{UNBALANCED ALTRUISM: SECURING THE INTERESTS OF IPS AND AGENCIES}

But moral frames of altruism play another important function, aside from enhancing social acceptability, in commercial surrogacy agreements: they help secure the results desired by IPs and agencies, especially when the surrogates' demands threaten their completion. Authors like Berkhout have already denounced that, since the goal of commercial surrogacy agencies is to ensure that the pregnancy is carried to term and the child is handed over to the IPs once born, whenever surrogates find their own ways to interpret surrogacy agreements different strategies are developed to marginalise their interpretation of the relation (Berkhout, 2008, p. 103). One such strategy, as I will explain below, relies on sexist stereotypes about women's self-sacrificing nature to dispel their complaints about contractual clauses or their relationship with IPs. Some commercial surrogacy industries (particularly, the U.S. and India, despite adopting different approaches) rely on an imbalance in the expected motivations of the parties. While IPs and agencies can justifiably act in ways that further their self-interest, surrogates are expected to have a natural disposition to sacrifice, even if that disposition is not reciprocated.

Let us recall that, in Cohen's framework, treating someone as a commodity amounts to seeing her as a "source of enrichment" (Cohen 2009, p. 40). In contrast, profit is not the key motivation when one is moved by his preferred form of reciprocity, communal reciprocity, in which the willingness to provide mutual help is enough to move people to relate with each other. How these motivations interact and how the parties employ them to justify their decisions in commercial surrogacy agreements often reflects the effect of some gender stereotypes that are prominent in some countries' culture, and that make the agreements' functioning reliant on gender inequalities. 
In her comprehensive research on SMO, the largest moderated public surrogacy website in the U.S., Zsuzsa Berend analyses the role of popular narratives about women's altruism in justifying the purpose and functioning of commercial surrogacy agreements. Across the different discussions that take place in SMO, Berend perceives a tendency for most surrogates to frame their relationship with IPs in intimate and altruistic terms. For instance, she remarks how difficult surrogates in SMO found it to talk about money in "such a personal and emotional" relationship (Berend, 2012, p. 924). Most surrogates characterised their experience in the first weeks after the agreement in terms of love and enthusiasm for the IPs, and some of them even recognised how they "let a lot go in financial terms" because of their love for their IPs (pp. 923-928). A lot of them also emphasised "the heart" in their comments, which, Berend claims, is consistent with the Western cultural understanding that sets love - an allegedly female characteristic - in opposition to calculation-more commonly associated with men (p. 923). In SMO, the surrogates' decisions are both "informed by and formulated with reference to powerful cultural symbols of the female nature as loving and nurturing, the importance of children and the taboo of commodifying human life within the contemporary reality of the market economy" (p. 924).

Moral frames about the surrogates' disposition to altruism and self-sacrifice help shape their relationship with their IPs in a non-commercial fashion during pregnancy. However, those references to altruism and the disposition to sacrifice themselves, Berend explains, are greatly undermined when their relationships with IPs finish after the child is born. Many surrogates in SMO see their desire to maintain their friendship with IPs broken after childbirth, whilst IPs usually try to redefine the relationship on their own terms. Berend notes how, when surrogates complained about the ungrateful behaviour of their IPs, the language of altruism disappears from their interactions, and is replaced by narratives more typical of market exchanges: since they understand the relationship in contractual terms, IPs reject the need for them to be grateful, especially considering that they had "paid in full" for the surrogates' services (p. 927). This frequent situation is characterised by an imbalance between the surrogates' motives, which commonly appeal to their disposition to sacrifice for others, and those of the IPs, who show that their only interest is paying a price for something they assume will get. When the IPs do not reciprocate the surrogates' altruistic behaviour with gratitude, veteran surrogates assumed the task of reminding disappointed beginners that creating life is a reward on its own (pp. 927-928).

The expectation that surrogates are inclined to engage in commercial surrogacy agreements by altruistic motivations, regardless of whether these are the same as those of the IPs, is further highlighted by the disparity between the agencies' preferred dispositions when recruiting surrogate candidates, and the way surrogates themselves report being treated by those agencies. As stated by Jacobson (2016, p. 60), "agencies are careful to avoid surrogates who appear to be "money hungry". This, in part, can be understood as a consequence of the traditional negative connotations about women's paid work that identify remunerated employment with selfishness, and staying at home with altruism ( $\mathrm{p}$. 67). At the same time, it also makes it easier for agencies to ensure that their candidates will be ready to make sacrifices that they would not find acceptable in any other job (see, p. 65). In contrast, many surrogates complain about agencies treating them in a work- 
like fashion, especially by controlling how they deal with the pregnancy-nourishment, healthy habits, etc. (p. 65). This imbalance between the motivations expected from surrogates and the agencies' zealous control over their pregnancy shows that the agencies' interest in finding candidates willing to make compromises for the sake of the agreement is not accompanied by a parallel interest in reciprocating them.

Narratives about the gift that life represents in itself also appear in other commercial surrogacy industries, outside the U.S. Surrogacy agencies in the Indian commercial surrogacy industry also support this idea, with the purpose of building an image of surrogates as self-sacrificing, naturally unselfish, women that are happy to undertake the process for no reason other than helping a third-party IP. Rudrappa and Collins (2015, p. 946) report that Indian agencies often describe surrogates as generous, yet poor individuals, and as "happy" to be of service to others, but who are secretive about their choice and unwilling to speak to clients. This monolithic image of surrogates emphasises the agencies' interest in justifying the surrogates' physical and emotional hardships through the process by portraying them as naturally disposed to sacrifice themselves for others.

Even though, as explained above, narratives of altruism are intended to dispel social concerns about the commodification of women and children through commercial surrogacy agreements, when analysed from a wider perspective that considers the entire range of motivations of all the parties to commercial surrogacy agreements, this construction of surrogates as naturally altruistic subjects might not prevent or diminish commodification.

To understand why that is the case, it is important to highlight that, regardless of the IPs' statements about why they enter into surrogacy agreements, their behaviour often departs from what might be generally understood as altruistic. Berend's study shows how the IPs alter the dispositional framework of their relationship with surrogates depending on what most satisfies their interests in each circumstance. For instance, whenever surrogates experience difficulties with their pregnancy, like the premature birth of the child, IPs tend to redefine their relationship from an "ongoing intimate friendship to a terminable business transaction" (Berend, 2012, p. 927). Berend herself reports how, in SMO, surrogates are encouraged to genuinely care for their gift to the intended parents from the early stages of pregnancy, when it is only an embryo or foetus (Berend, 2010). Yet, when miscarriages occur, there is no parallel encouragement on IPs to care about the emotional situation of the surrogate, who is left "with a diffuse obligation to mourn the loss that is not mourned by anyone else", while the IPs can "walk away as if from a failed transaction" (p. 254).

This shows how, even if, in the beginning, they might be willing to treat surrogates in ways that depart from those typical of market exchanges, IPs deal with potential threats to the end-result of the contract — them acquiring a healthy child — very similarly to how a customer deals with manufacturing defects or delivery delays in a product she has just acquired. Unlike surrogates, who are encouraged to compromise their expectations and rights in the agreement for the sake of a greater good-making other people happy by bringing a new life to the world-, IPs are never expected to concede on any of the terms of the contract. Rather, as Anderson suggests, the agencies' role in commercial surrogacy 
agreements constitutes exercising different kinds of pressure on surrogates to ensure that what was promised to IPs as part of the contract is adequately fulfilled (Anderson, 1990, p. 76). That pressure, as Berend's study shows, is further enhanced by actors like veteran surrogates, who constantly remind newcomers of their duty to sacrifice for others without expecting anything in return, and discipline complaints about lack of reciprocation from IPs by relying on ideas like "acceptance and resignation" (Berend, 2016, p. 88). On the contrary, those surrogates who accept that their desire for friendship is not shared by IPs are rewarded with compliments (p. 97). Interestingly, while surrogates are encouraged not to develop any feeling of attachment to the foetus or the baby (p. 81-82), "[t] he emotional connection surrogates feel or wish to feel to their couple is easier to understand if we consider that surrogacy involves the giving of oneself that in the modern Western cultural context is appropriate only in loving personal relationships" (p. 83).

This stark contrast between the behaviour and dispositions expected of surrogates, on the one hand, and those expected of IPs, on the other, indicates that the presence of altruism in U.S. and Indian commercial surrogacy agreements does not diffuse commodification by agencies and IPs, as it works as a device to promote the IPs' interests by encouraging surrogates to act in those ways that are better suited to meet other people's demands. The presence of altruism in these agreements might ease social anxieties about perceived commodification, but it does not lessen the commodification of the gestational work of women, as it allows agencies and IPs to obtain greater benefits from them. Following Cohen's characterisation of communal reciprocity (see above, Section 3.2.), the behaviour of agencies and IPs in these situations does not seem to make the requirement to serve others for strictly non-instrumental, non-egoistic, reasons materialise. Instead, they portray a scenario in which IPs and agencies have an interest in depicting surrogates as naturally self-sacrificing to ensure that they act in ways that get them what they want.

Once again, this discursive strategy fits within wider gender narratives that construct women as naturally inclined to sacrifice for others. This type of dynamic, in which one group pressures another to behave altruistically, was already examined by Folbre's analysis of gender inequalities in the field of family care. Folbre points out that "since it is costly for individuals to make sacrifices, groups that develop ways of persuading - or pressuring - individuals to sacrifice for the 'greater good' may enjoy some advantages" (Folbre, 2012, p. 604). Folbre herself summarises this idea in the following way: "selfish individuals fare best in a world in which others are altruistic" (p. 606). In commercial surrogacy agreements, women's sacrifices in the field of reproduction are prompted in specific ways. In the U.S., these include, as mentioned above, veteran surrogates reminding less experienced surrogates of the intrinsic reward of creating a new life for others, and agencies emphasising the importance of altruistic motivations when recruiting them. In India, agencies' depictions of surrogates as happy to be of service for others frame their relationships in a way that justifies sacrifices without imposing an expectation on IPs to reciprocate them. In both contexts, the functioning of commercial surrogacy relies on common narratives that draw a clear contrast between surrogates, whose appropriate function is to think about the IPs' happiness or the greater good of creating life, and the IPs, who can adequately treat surrogates on the basis of self-interest, and care for the surrogates' wellbeing only inasmuch as it affects the child they want to raise as their own. 
To the extent that narratives of altruism within these contexts aim at making it easier for IPs and agencies to profit from women's bodies and labour, we can at least suspect that they do not undermine commodification. If anything, as stated above, they reinforce it. This representation of surrogates as naturally self-sacrificing subjects might fuel the idea that women's main social function is to put their bodies at the service of market demand. Before commercial surrogacy reached its current dimension, these traditional narratives that institutionalise the image of women as breeders (Dillaway, 2008, p. 317) upheld their subordination to men within marriage and the family. Nowadays, they serve an additional purpose: securing the human means necessary to satisfy the market demand for children. Women's reproductive capacities are sometimes seen as an asset that they should surrender to others' demands. Berkhout (2008, p. 100) points out that these patriarchal dynamics include the branding of those women who lack the desire to get pregnant as "selfish, unhappy and emotionally deviant". According to the author, research around the acceptability of reproductive technologies still detects a discursive connection between female fertility and personal identity, "as well as feelings of social exclusion among childless women" (p. 100). In these contexts, commercial surrogacy agreements rely on essentialist views of women as self-sacrificing and on notions that connect womanhood to a desire for pregnancy. At the same time, people who are wealthy and have a desire for children are told by surrogacy agencies that it is appropriate to use their economic resources to obtain a benefit from surrogates without making reciprocal sacrifices.

\section{COMMERCIAL SURROGACY AND GENDER INEQUALITIES}

Given its reliance on traditional assumptions about women's disposition to altruism, and the way these assumptions make it easier for IPs and agencies to obtain sacrifices from surrogates, in countries like the U.S. and India commercial surrogacy can entrench gender stereotypes that have historically upheld gender inequalities, especially in reproduction and family relationships.

The fact that some surrogacy markets rely on common notions about women's self-sacrificing nature and their altruistic desire to bring a new life to the world does not mean that all women will be equally disadvantaged. Drawing on Spelman's critique to gender realism (Spelman, 1988), Young (1994) highlights how it would be inadequate to conceive of women's experience of gender relations as completely independent from other conditions like class, race, or nationality ${ }^{7}$. Yet, this is not incompatible, in my view, with the argument that ideas about womanhood, and the expectations that such ideas assign to women, play a key role in the functioning of the U.S. and India's commercial surrogacy industries, and that the possibility of the practice becoming more prevalent might not counter, but rather reinforce, gender inequalities. Young herself points out that, even if

\footnotetext{
${ }^{7}$ I would like to thank two anonymous reviewers for pointing out that ignoring the consequences of class, race, nationality, and other conditions in the operations of commercial surrogacy agreements would render my approach to commercial surrogacy from the perspective of gender inequality incomplete, and vulnerable to the critique that it flattens out gender.
} 
conditions like class affect women's experiences and relations, we should not assume that cross-class relations are not gendered (Young, 1994, p. 720).

Following this line of thought, ethnographic work in contexts like the U.S., India, and Israel clearly states that traditional views of womanhood affect the relations between the parties and their expected behaviour in commercial surrogacy agreements and are also fundamental for the agreements' social acceptability and functioning. The avoidance of women perceived as selfish in agencies' recruitment in the U.S. (Jacobson, 2016, p. 60), the construction of Indian women as happy to help in the agencies' interactions with IPs (Rudrappa and Collins, 2015, p. 946), or the importance attached to connection or clicking with IPs in Israel (Teman, 2010, p. 136) are just a few examples of the importance of gendered expectations in commercial surrogacy agreements. The fact that such expectations might impact women differently does not necessarily mean that they cannot be described as instances of gender inequality, especially considering that they are not commonly attached to men's acceptable or expected behaviour. Similarly, the fact that, because of "the broader context of socio-economic stratification" in reproduction (Smietana, 2017, p. 5), uppermiddle class intended mothers are often the ones to commission commercial surrogacy agreements does not mean that gendered constructions about women's natural disposition to care and act altruistically are irrelevant to make commercial surrogacy agreements more advantageous for IPs. It may be the case that, because of the intersection between class and gender present in reproductive stratification, upper-middle class women are not affected by those constructions in the same way as those who "come from lower social class backgrounds" (p. 5). Yet, this does not necessarily weaken the argument that those constructions give rise to inequalities that may be adequately called gender inequalities.

Such an argument is, in my point of view, reinforced by the fact that common associations between care, altruism, and motherhood, on the one hand, and womanhood, on the other, also affect the position and expectations of IPs in surrogacy agreements depending on their gender. For instance, Teman reports how, in Israel, "[i]ntended fathers were involved in the negotiations over the contract, financial decisions during surrogacy, and the birth itself, but tended to step aside during other aspects of the process", most relevantly the emotional aspect of building an affective relation with the surrogate (Teman, 2010, p. 138). In the U.S., Berend's research depicts a similar divide: while intended mothers often develop a link of "fictive kinship" with the surrogate (2016, p. 81), "intended fathers are the focus of bonding only when they are gay" (p. 83) ${ }^{8}$. So, even if, because of their class, intended mothers are not affected by the gendered role division in the same way as surrogates, their role in commercial surrogacy agreements also draws on that division, since emotional and affective work is commonly considered their parcel, while financial arrangements tend to be the realm for men.

\footnotetext{
${ }^{8}$ It is important to acknowledge that, as Berend suggests $(2016$, p. 83$)$ the exclusion of heterosexual intended fathers from the emotional duties of the relation have to do with the "adulterous connotations of procreation outside of marriage" (p. 83). But we should not rule out that social expectations that separate men from care work, for instance by assuming that care is something that men are necessarily bad at (see Elliot, 2016, p. 15) also play a role in reinforcing those connotations.
} 
The surrogates' relationships with gay IPs also show that sexual orientation might change the way gender inequalities manifest in commercial surrogacy when compared with the surrogates' relationships with heterosexual IPs. The fact that, as reported by Berend, bonding with intended fathers is only common among U.S. surrogates when they are gay shows that the intersection between gender and sexual orientation-like the intersection between gender and class - also affects the ways in which inequalities appear in the relations among the genders. In fact, Smietana's research on the relationships between surrogates and gay IPs suggests that "surrogacy was founded on socio-economic class stratification, where the surrogates occupied lower middle-class positions, and gay fathers higher middle-class ones" (Smietana, 2017, p. 9). At the same time, he adds that "economic narratives were also shaped by a normative frame, according to which women who become surrogates should be motivated by a positive affect rather than economic pressure" (p. 9). So, even if affected by the intersection of class and sexual orientation, common gender narratives that are fundamental for the functioning of commercial surrogacy still play a role in the relationships between surrogates and gay IPs. In narratives that connect surrogates with an expectation to be moved by altruism in particular, ethnographic research suggests that, even if gender inequalities do not affect all women equally - and do not affect their relationships with all men equally_-, commercial surrogacy relies on traditional stereotypes about women that justify, and reinforce, current gender inequalities. Narratives about women's allegedly altruistic nature imply that people can legitimately expect from them sacrifices that are typical of an others-regarding disposition that is (at least) not (as commonly) expected from men.

\section{COMMERCIAL SURROGACY, THE SOCIAL VALUE OF CARE WORK, AND GENDER INEQUALITIES}

In the previous two sections, I have tried to explain that common gendered narratives in certain surrogacy contexts, most relevantly those that depict women as naturally inclined to self-sacrifice, play two major functions in commercial surrogacy agreements: making them socially acceptable, and enhancing the IPs' and agencies' capacity to make sure that their interests are satisfied in ways that demand non-reciprocated sacrifices from surrogates. Jacobson claims that some of the undesirable consequences of commercial surrogacy agreements for surrogates arise from culturally entrenched fears to consider surrogacy work. According to the author, "[s]urrogacy is work, and much of that workincluding protecting the industry from scrutiny-falls on the backs of the surrogates ... That work is more than simply hidden: it is deliberately obscured (emphasis added) to make it culturally palatable. The obscuring of surrogate labour allows surrogacy to function in the United States, yet I would argue that it poses potential costs for individual surrogates, IPs, and women more generally" (Jacobson, 2016, 177-178). This obscuring of surrogacy as work is, Jacobson suggests, rooted in "deep-seated anxieties about the intersection of the market and reproduction, women and work, and the commodification of humans and their biological products" (p. 177).

Jacobson's statement suggests that, in environments like those U.S. states where commercial surrogacy is legal, the practice still navigates grey areas in which commodified gestation is allowed, but not completely considered work, even if there 
is "demand and support for surrogacy" (p. 177). In those grey areas, surrogates are the ones to suffer the consequences of different social stereotypes that consider gestation incompatible with remunerated work, as the (socially imposed) need to characterise their transaction with IPs as altruistic makes it easier, along the lines of my arguments in Section 4, to extract greater sacrifices from them. Obscuring surrogacy as work is, as Jacobson claims, rooted in contextual cultural assumptions. This is well exemplified by the case of commercial surrogacy in Russia, which does not rely on a conceptualisation of surrogates as naturally inclined to altruism; rather they are understood as parties in a business relation (Smietana, Rudrappa and Weis, 2021). The stigma faced by Russian surrogates is a good example of the disincentives U.S. surrogates might have for labelling their gestation as work, and the incentives that lead them to label their work along narratives of altruism and gift-giving. Khvorostyanov and Yeshua-Katz (2020, pp. 481-482) state that despite their work being construed as "paid work that may not be highly respected but carries an important social function", in online surrogacy forums surrogates are considered greedy and bad mothers, which "enables control over women's bodies and challenges the source of their income".

From the perspective of gender equality, the comparison between commercial surrogacy agreements in the U.S. and Russia implies that, in certain contexts, women who decide to become surrogates have to opt between being stigmatised as selfish and greedy, or depict their motivations in altruistic terms, as a result of common narratives about women's disposition to self-sacrifice, which leads to worse working conditions for them. However, alongside social anxieties about the commodification of gestation (which, as explained above, are key to understand the parties' strategies to justify kinship connections), pregnancy and other forms of nurturance are also "obscured" as work as a result of culturally entrenched, essentialist divisions, that tend to consider care work in general as predominantly female and of lower value, and occupations related to finance and STEM (Science, Technology, Engineering, and Math) careers as predominantly male and of higher value. The prevalence of those divisions can be seen, for instance, in women's own underestimation of their competence in STEM, prevalent in the U.S. context (Fine, 2010), or in the limited opportunities afforded to women by the Russian labour market, where "male-dominated occupations are better paid and considered more prestigious than jobs primarily held by women" (Khvorostyanov and Yeshua-Katz, 2020, p. 482). It should be noted, those divisions also affect the distribution of, and the social value attributed to, unremunerated care work within the home.

Both these findings indicate that the mere presence of the market and economic compensation in an activity - in this case reproductive care and, in particular, gestationor its recognition as remunerated "work", might not automatically break traditional assumptions about women's work or empower them in family and wider social relationships. Against Jacobson's suggestion that de-obscuring paid gestation as "work" would strengthen women's bargaining power, Berend (2016, p. 59) argues that, even if gestation is now able to be remunerated via commercial surrogacy agreements, U.S. candidates still consider their husband's support essential to decide becoming surrogates. In Russia, even if surrogacy is paid, gestation is still considered of inferior occupational value (Khvorostyanov and Yeshua-Katz, 2020, p. 482). 
Jacobson's argument about the social anxieties around the commodification of gestation could explain, in part, why current commercial surrogacy agreements reinforce, and rely on, gender inequalities. Gestation is (for now, and overwhelmingly) women's labour, and obscuring it as "work" can have a negative impact on the social value attributed to other forms of care work, still largely performed by women. This position suggests that surrogates could escape most of their current disadvantages in commercial surrogacy agreements if their societies naturalised thinking of gestation as remunerated care work. However, the anxieties Jacobson has in mind are not the only, arguably not even the main, factor that explains the social undervaluation of care work that affects commercial surrogacy and many other activities. In my view, it is possible to argue that gestation and other forms of nurturance are undervalued as the result of gendered role divisions that uphold at least two additional ideas about care work: 1) that it is predominantly women's, and not men's, work, and 2) that it has less value than male-dominated occupations. Both these ideas are independent from social anxieties about the commodification of gestation, as many other care-related occupations which are widely accepted as adequate spaces for market transactions are still highly undervalued in the labour market. This suggests that overcoming the obscuring of gestation (and other care-related occupations) as work may require other courses of action, different from naturalising market transactions in the field of reproduction.

Following Elliot (2016), this could be achieved by implementing a comprehensive scheme of state policies including, inter alia, compulsory paid parental leave, which involve men in the world of household care. This might be particularly appropriate to lessen or even eliminate the impact of gender imbalances arising from the distribution of domestic work among heterosexual couples (see, for instance, Eurostat, 2020, p. 24). Elliot (2016, p. 4) supports the idea of promoting "caring masculinities" as an instance of a "gender equality intervention (Hanlon, 2012) that seeks to integrate values and practices of care and interdependence, traditionally though not unescapably associated with women, into masculine identities". Men's involvement in care, especially when promoted via state support, might contribute to erase social perceptions about its lesser value: by actively supporting the entire society's implication in care, institutions might highlight its role as an essential activity.

Furthermore, these schemes might help escape cultural stereotypes about women's endemic inclination to self-sacrifice, by promoting what Lynch, Baker, and Lyons (2009) call "affective equality", in other words, the equal distribution of attitudes such as love, care, and solidarity. These attitudes form the affective system that, according to the authors, is "one of the main social systems, along with the economic, political, and sociocultural systems, from which equality or inequality emerge". By involving men in activities within the affective system, the above attitudes might cease to be perceived as exclusively female, which could undermine common confusions between biology and culture, that fuel conceptualisations of women as naturally inclined to nurturance because of their biological capacity to gestate children (Nagel, 1997; Wilson, 2004). This, Elliot concludes, "can effectively change gender" (Elliot, 2016, p. 16).

Therefore, even if some social anxieties about the intersection between gestation and the market obscure gestational work, that does not mean that those committed with 
gender equality should embrace the naturalisation of market transactions in gestation as a means to advance a higher social valuation for gestational work. Nor does it mean that advancing gender equality should lead us to dispel all social anxieties around the commodification of reproduction.

Some such anxieties are connected to concerns about the status of children and the grounds to establish custody rights before the law. According to Anderson, legalising commercial surrogacy might open the door to disputes about legal custody over children being resolved based on payment (Anderson, 2000, p. 21). This, the author argues, should be a cause for concern as, instead of focusing on the best interests of the child, legal disputes about custody rights might be resolved in the same way as disputes about property rights (p. 20). This would depart, the author claims, from "regarding parental rights over children as trusts" to be exercised in their best interest ${ }^{9}$.

Normalising market exchanges in reproduction, like the ones that take place in commercial surrogacy agreements, might not, therefore, be the best route available to challenge gender inequalities in care and reproduction, because gestational labour is obscured, in many societies, as the result of cultural assumptions that go beyond fears about commodifying reproduction. Those assumptions have to do with the value attributed to (remunerated and unremunerated) care work, its consideration as predominantly women's realm, and the social prevalence of narratives that depict women as more inclined to altruism and self-sacrifice than men. Identifying gestation and family care as "work", and as a socially valuable one, need not rely on dispelling cultural anxieties about the operation of the market in reproduction, especially those related to the commodification of legal custody rights over children. The commercial surrogacy market in Russia, where surrogates are treated as parties to any other market transaction, suggests that treating gestation as any other market activity does not necessarily challenge social assumptions about the value of care work. Instead, involving men and public institutions in the affective system might be more effective in enhancing the social valuation of care work, and advance women's equal participation in remunerated and non-remunerated labour ${ }^{10}$, without prompting concerns about the commodification of legal custody rights over children.

\section{Conclusion}

Commercial surrogacy has become increasingly relevant in recent years and has attracted the attention of several academics, who have developed a growing body of ethnographic fieldwork on the subject. That fieldwork permits critical approaches to the practice to draw comparisons and analyse how different cultural settings affect the positions of the parties in these agreements. In this paper, I have focused on commercial surrogacy's implications from gender equality in some of the most relevant contexts

\footnotetext{
${ }^{9}$ In reply to Anderson, see McLachlan and Swales, 2000; 2007; 2009.

${ }^{10}$ As theorised by Okin (1989, pp. 138-39), these gendered divisions of labour "involves women in a cycle of socially caused and distinctly asymmetric vulnerability" in which they are expected to be the primary caretakers within the household and, at the same time, are disadvantaged in "the world of wage work" because the labour market "is still largely structured around the assumption that "workers' have wives at home".
} 
covered by those ethnographies. Those implications are commonly portrayed in the moral frames used by the parties to justify their decisions in commercial surrogacy agreements. Commonly, such moral frames rely on common stereotypes about women's nature as self-sacrificing subjects that have detrimental effects for surrogates, and that may have detrimental effects for gender equality in general. Even if highly stratified, it is still both possible and desirable to analyse commercial surrogacy along the lines of gendered narratives that attach certain expectations to women because of the fact of them being women, and to rise concerns about the practice's reinforcement of, and reliance on, social stereotypes about women's self-sacrificing motivations.

Whether these concerns mean that the growing popularity of commercial surrogacy alone will make overall gender inequalities worse in those contexts where the practice is legal might depend on factors beyond the practice itself. On the one hand, legal commercial surrogacy coexists with other trends and practices that rely on traditional stereotypes about women's nature that are detrimental for gender equality. Therefore, isolating the specific impact of commercial surrogacy for gender inequalities might be too complex and speculative a task ${ }^{11}$. On the other, narratives relying on stereotypes that justify gender inequalities, such as those present in commercial surrogacy agreements, are now challenged by changes in men and women's social roles. Nevertheless, this should not prevent critical assessment of alternative forms of parenthood and reproduction and their potential to promote, or hinder, our societies' drive to greater justice in gender relations. Nor should it stop critical inquiries from highlighting that, even if such forms of parenthood and reproduction can change how we think about traditional institutions like the family in some respects (such as kinship), they may still thrive, in some contexts, as a result of cultural assumptions that reinforce oppressive stereotypes about women's nature. Even if its impact in gender relationships is enhanced, or challenged, by other developments, commercial surrogacy and other reproductive technologies should continue to be evaluated as contributing, or counteracting, forces for gender equality.

\section{REFERENCES}

ALMELING, R. (2006), "Why do you want to be a donor?": gender and the production of altruism in egg and sperm donation', New Genetics and Society, 25(2), pp. 143157. https://doi.org/10.1080/14636770600855184

ANDERSON, E. (1990) 'Is Women's Labor a Commodity?', Philosophy \& Public Affairs, 19(1), pp. 71-92.

ANDERSON, E. (2000), 'Why Commercial Surrogate Motherhood Unethically Commodifies Women and Children: Reply to McLachlan and Swales', Health Care Analysis, 8(1), pp. 19-26. https://doi.org/10.1023/A:1009477906883

\footnotetext{
${ }^{11}$ As highlighted by an anonymous reviewer, other genetic and reproductive technologies, such as stemcell research and egg donation, rely on parallel gendered assumptions about women's altruism and men's legitimate selfishness (Almeling, 2006, pp. 150-151; Thompson, 2012).
} 
BEREND, Z. (2010), 'Surrogate Losses: Understandings of Pregnancy Loss and Assisted Reproduction among Surrogate Mothers', Medical Anthropology Quarterly, 24(2), pp. 240-262. https://doi.org/10.1111/j.1548-1387.2010.01099.x

BEREND, Z. (2012), 'The Romance of Surrogacy', Sociological Forum, 27(4), pp. 913936. https://doi.org/10.1111/j.1573-7861.2012.01362.x

BEREND, Z. (2016), The Online World of Surrogacy. New York: Berghahn Books. https:// doi.org/10.2307/j.ctvr6951j

BERKHOUT, S.G. (2008), 'Buns in the Oven: Objectification, Surrogacy and Women's Autonomy', Social Theory and Practice, 34(1), pp. 95-117. https://doi.org/10.5840/ soctheorpract 20083415

BERNARDO, S. AND BERNARDO, K. (2007), 'Assisted Reproductive Technologies: Egg Donation and Surrogacy Arrangements in Law and Practice', Bloomberg Corporate Law Journal, 2, pp. 406-414.

BIRENBAUM-CARMELI, D. AND MONTEBRUNO, P. (2019), 'Incidence of Surrogacy in the USA and Israel and Implications on Women's Health: A Quantitative Comparison', Journal of Assisted Reproduction and Genetics, 36, pp. 2459-2469. https://doi.org/10.1007/s10815-019-01612-9

CAAMANO, J.M. (2016), 'International, Commercial, Gestational Surrogacy through the Eyes of Children Born to Surrogates in Thailand: A Cry for Legal Attention', Boston University Law Review, 96(2), pp. 571-607.

COHEN, G.A. (2000), If You're an Egalitarian, How Come You're So Rich? Cambridge MA: Harvard University Press.

COHEN, G.A. (2009), Why Not Socialism? Princeton: Princeton University Press.

DILlAWAY, H. (2008), 'Mothers for Others: A Race, Class and Gender Analysis of Surrogacy', International Journal of Sociology of the Family, 34(2), pp. 301-326.

DOW, K. (2015), ““A Nine-Month Head-Start”: The Maternal Bond and Surrogacy', Ethnos, 82(1), pp. 86-104. https://doi.org/10.1080/00141844.2015.1028957

ELLIOT, K. (2016), 'Caring Masculinities: Theorizing an Emerging Concept', Men and Masculinities, 19(3), pp. 240-259. https://doi.org/10.1177/1097184X15576203

EUROSTAT. (2020), The life of women and men in Europe. Available at: https://ec.europa. eu/eurostat/cache/infographs/womenmen/index.html?lang=en [Accessed: 30 June 2021].

FENTON-GLYNN, C. (2019), 'Surrogacy: Why the world needs rules for "selling" babies', BBC News, 25 April. Available at: https://www.bbc.com/news/health-47826356 [Accessed: 12 January 2021].

FINE, C. (2010), Delusions of Gender. London: Icon Books. 
FOLBRE, N. (2012), 'Should Women Care Less? Intrinsic Motivation and Gender Inequality’, British Journal of Industrial Relations, 50(4), pp. 597-619. https:// doi.org/10.1111/bjir.12000

FONTANELLA-KHAN, A. (2010), India, the Rent-a-Womb Capital of the World, Slate. Available at: http://www.slate.com/articles/double_x/doublex/2010/08/india_the rentawomb_capital_of_the_world.html [Accessed: 12 November 2020].

GOFFMAN, E. (1974), Frame analysis: An essay on the organization of experience. Boston: Northeastern University Press.

HANLON, N.(2012), Masculinities, Care andEquality: Identity and Nurture in Men's Lives. Basingstoke, UK: Palgrave Macmillan. https://doi.org/10.1057/9781137264879_3

JACOBSON, H. (2016), Labor of Love. New Brunswick: Rutgers University Press.

JAISWAL, S. (2012), 'Commercial Surrogacy in India: An Ethical Assessment of Existing Legal Scenario from the Perspective of Women's Autonomy and Reproductive Rights', Gender, Technology and Development, 16(1), pp. 1-28. https://doi. org/10.1177/097185241101600101

KHVOROSTYANOV, N. AND YESHUA-KATZ, D. (2020), 'Bad, Pathetic and Greedy Women: Expressions of Surrogate Motherhood Stigma in a Russian Online Forum', Sex Roles, 83(7), pp. 474-484. https://doi.org/10.1007/s11199-020-01119-z

LIMKI, R. (2018), 'On the coloniality of work: Commercial surrogacy in India', Gender, Work \& Organization, 25(4), pp. 327-342. https://doi.org/10.1111/gwao.12220

LYNCH, K., BAKER, J., AND LYONS, M. eds. (2009), Affective Equality: Love, Care and Injustice. New York: Palgrave Macmillan.

MCLACHLAN, H. AND SWALES, K., (2000), 'Babies, Child Bearers and Commodification: Anderson, Brazier et al., and the Political Economy of Commercial Surrogate Motherhood', Health Care Analysis, 8(1), pp. 1-18.

MCLACHLAN, H. AND SWALES, K., (2007), From the Womb to the Tomb: Issues in Medical Ethics, Glasgow: Humming Earth.

MCLACHLAN, H. AND SWALES, K., (2009), 'Commercial Surrogate Motherhood and the Alleged Commodification of Children: A Defence of Legally Enforceable Contracts', Law and Contemporary Problems, 72, pp. 91-108.

NAGEL, T. (1997), 'Justice and Nature', Oxford Journal of Legal Studies, 17(2), pp. 303-321. https://doi.org/10.1093/ojls/17.2.303

NELKIN, D. (1992), Controversy: Politics of Technical Decisions. Newbury Park: Sage.

OKIN, S.M. (1989), Justice, Gender, and the Family. New York: Basic Books.

PANDE, A. (2010), "“At Least I Am Not Sleeping with Anyone”: Resisting the Stigma of Commercial Surrogacy in India', Feminist Studies, 36(2), pp. 292-312. 
RAGONÉ, H. (1996), 'Chasing the Blood Tie: Surrogate Mothers, Adoptive Mothers and Fathers', American Ethnologist, 23(2), pp. 352-365. https://doi.org/10.1525/ ae.1996.23.2.02a00090

RIBEN, M. (2015), 'American Surrogate Death: NOT the First', The Huffington Post. Available at: http://www.huffingtonpost.com/mirah-riben/american-surrogatedeath-_b_8298930.html [Accessed: 10 November 2020].

RUDRAPPA, S. AND COLLINS, C. (2015), 'Altruistic Agencies and Compassionate Consumers: Moral Framing of Transnational Surrogacy', Gender \& Society, 29(6), pp. 937-959. https://doi.org/10.1177/0891243215602922

RUDRAPPA, S. (2016), ‘Why India’s New Surrogacy Bill Is Bad for Women', HuffPost, 26 August. Available at: https://www.huffpost.com/entry/why-indias-new-surrogacybill-is-bad-for-women_b_57c075f9e4b0b01630de83ad [Accessed: 14 June 2021].

SATZ, D. (1992), 'Markets in Women's Reproductive Labor', Philosophy \& Public Affairs, 21(2), pp. 107-131.

SCHEPER-HUGHES, N. (2001), 'Bodies for Sale - Whole or in Parts', Body \& Society, 7(2-3), pp. 1-8. https://doi.org/10.1177/1357034X0100700201

SMIETANA, M. (2017), 'Affective De-Commodifying, Economic De-Kinning: Surrogates' and Gay Fathers' Narratives in U.S. Surrogacy', Sociological Research Online, 22(2), pp. 163-175. https://doi.org/10.5153/sro.4312

SMIETANA, M., RUDRAPPA, S. AND WEIS, C. (2021), 'Moral frameworks of commercial surrogacy within the US, India and Russia', Sexual and Reproductive Health Matters, 29(1), pp. 1-17. https://doi.org/10.1080/26410397.2021.1878674

SPELMAN, E. (1988), Inessential Woman. Boston: Beacon Press.

STRATHERN, M. (1992), After Nature: English Kinship in the Late 20th Century. Cambridge: Cambridge University Press

TEMAN, E. (2003), "The Medicalization of "Nature" in the "Artificial Body": Surrogate Motherhood in Israel', Medical Anthropology Quarterly, 17(1), pp. 78-98. https:// doi.org/10.1525/maq.2003.17.1.78

TEMAN, E. (2010), Birthing a Mother. Berkeley: University of California Press. https:// doi.org/10.1525/9780520945852

The Surrogacy (Regulation) Bill. 2019. (Lok Sabha Bill No. 156 of 2019). New Delhi: PRS India.

THOMPSON, C. (2005), Making Parents. Cambridge MA: The MIT Press.

THOMPSON, C. (2012), 'Three Times a Woman'. CSW's Life (Un)Ltd project, UCLA. Available at: https://www.youtube.com/watch?v=tR_as9K3edM.

VROUSALIS, N. (2012), 'Jazz Bands, Camping Trips and Decommodification: G. A. Cohen on Community', Socialist Studies, 8(1), pp. 141-163. https://doi. org/10.18740/S4MG6J 
WEIS, C. (2019) 'Situational ethics in a feminist ethnography on commercial surrogacy in Russia: Negotiating access and authority when recruiting participants through institutional gatekeeper', Methodological Innovations, 12(1), pp. 1-10. https://doi. org/10.1177/2059799119831853

WILSON, C. (2004), Moral Animals: Ideals and Constraints in Moral Theory. Oxford: Clarendon Press. https://doi.org/10.1093/0199267677.001.0001

YOUNG, I.M. (1994), 'Gender as Seriality: Thinking about Women as a Social Collective', Signs, 19(3), pp. 713-738. https://doi.org/10.1086/494918

Received: June $30^{\text {th }} 2021$

Accepted: October $4^{\text {th }} 2021$ 